\title{
Emodin induces collagen type I synthesis in Hs27 human dermal fibroblasts
}

\author{
PARKYONG SONG ${ }^{1}$, HAN-SEUL JO $^{2}$, WAN-SEOG SHIM ${ }^{1}$, YANG WOO KWON ${ }^{2}$, \\ SUNGWON BAE ${ }^{2}$, YONGHOON KWON ${ }^{3}$, BAKHOVUDDIN AZAMOV ${ }^{1}$, JIN HUR ${ }^{1}$, \\ DONGJUN LEE ${ }^{1}$, SUNG HO RYU ${ }^{3}$ and JONG HYUK YOON ${ }^{2}$
}

${ }^{1}$ Department of Convergence Medicine, Pusan National University School of Medicine, Yangsan 50612; ${ }^{2}$ Neurodegenerative Diseases Research Group, Korea Brain Research Institute, Daegu 41062;

${ }^{3}$ Department of Life Sciences, Pohang University of Science and Technology, Pohang 37673, Republic of Korea

Received July 17, 2020; Accepted December 17, 2020

DOI: $10.3892 / e t m .2021 .9864$

\begin{abstract}
Fibrillar collagen and elastic fibers are the main components of the dermal extracellular matrix (ECM), which confers mechanical strength and resilience to the skin. In particular, type I collagen produced by fibroblasts is the most abundant collagen that determines the general strength of the ECM, thereby contributing to the prevesntion of the skin-aging process. Although the natural anthraquinone derivative emodin (1,3,8-trihydroxy-6-methylanthraquinone) exerts numerous beneficial effects, including antiviral, anticancer, anti-inflammatory and wound-healing effects in diverse cells, the effect of emodin on collagen expression or skin aging is not fully understood. The present study demonstrated that exposure to emodin increased type I collagen synthesis in a concentration- and time-dependent manner in Hs27 human dermal fibroblasts. Subsequent experiments showed that emodin strongly increased collagen type I levels without altering cell proliferation or cellular matrix metalloproteinase-1 (MMP-1) expression. Additionally, it was determined that increased phosphorylation of 5' AMP-activated protein kinase, following emodin treatment, was responsible for increased type I collagen synthesis. These findings clearly indicate that emodin plays an important role in collagen type I synthesis in dermal fibroblasts, thereby making it a potential drug candidate for treating skin aging and wrinkles.
\end{abstract}

\section{Introduction}

Dermal fibroblasts are major skin components that produce extracellular matrix (ECM) for the modulation of cellular

Correspondence to: Dr Jong Hyuk Yoon, Neurodegenerative Diseases Research Group, Korea Brain Research Institute, 61 Cheomdan-ro, Daegu 41062, Republic of Korea

E-mail: jhyoon@kbri.re.kr

Key words: AMPK, collagen, dermal fibroblast, emodin, ERK, wrinkle structure. ECM homeostasis is regulated by fatty acid oxidation and glycolysis in dermal fibroblasts, thereby leading to skin ECM accumulation and degradation (1). As a major protein in the ECM, collagen is responsible for supporting cellular structure and skin stability and elasticity $(2,3)$. Type I collagen is the most abundant class present in humans (4) and promotes cell proliferation, as well as tissue connections and attachments through collagen-binding integrins and discoidin domain receptor 2 (5). Collagen synthesis is regulated by several cytokines at both the transcriptional and posttranscriptional levels (6). For example, insulin-like growth factor-I (IGF-I) treatment increases procollagen synthesis, whereas cycloheximide completely inhibits IGF-1-induced collagen expression (7). Moreover, transforming growth factor- $\beta$ (TGF- $\beta$ ) signaling contributes to increased collagen expression by suppressing microRNA-196a levels (8) or by activating the extracellular signal-regulated kinase $1 / 2$ (ERK1/2) pathway (9). Once procollagen is synthesized, it is further modified by the addition of hydroxyl groups to proline and lysine residues, followed by peptide cleavage by collagen peptidase and fibril assembly by lysyl oxidase to form a mature collagen fibril (10-12). Collagen is negatively regulated by interferon- $\alpha$ (IFN- $\alpha$ ), IFN- $\gamma$ and matrix metalloproteinase (MMP)-induced proteolysis $(13,14)$. Additionally, activator protein-1 (AP-1), a transcription factor in fibroblasts, is activated by UV irradiation to decrease collagen production and increase $M M P$ gene transcription, thereby increasing collagen degradation (15). Thus, skin aging is accompanied by the accumulation of damaged ECM components, as well as reduction of collagen in dermal cells, which consequently decreases the fibroblast-ECM interaction and results in skin shrinkage and undesirable wrinkle effects. By contrast, stimulation of type I collagen expression significantly improves tissue recovery and appearance (16). Interestingly, several studies show that polyphenolic compounds, such as flavonoid glycosides, ginsenosides, or catechins, stimulate type I collagen biosynthesis (17-19).

Emodin (1,3,8-trihydroxy-6-methylanthraquinone) is a natural anthraquinone derivative belonging to the polyphenol family and found in various Chinese herbs, such as Rheum palmatum, Polygonum cuspidatum and Polygonum 
multiflorum $(20,21)$. Numerous studies report that emodin exerts various biological effects, including antiviral, anti-allergic, anticancer, immunosuppressive, anti-inflammatory and neuroprotective effects (22-26). Interestingly, previous studies also suggest that natural anthraquinones, such as emodin and parietin, are implicated in the wound-healing process (27-29), which is strongly associated with collagen metabolism (30). Although Lin et al (31) have reported that emodin improves wound healing by increasing the expression of cytokines, such as monocyte chemoattractant protein-1, interleukin (IL)-1 $\beta$, and vascular endothelial growth factor, in a burn-wound mouse model, the association between emodin and type I collagen expression and the cellular mechanism by which emodin exerts its effect in human dermal fibroblast cells remain unclear. Therefore, the present study investigated whether emodin induced increase in type I collagen synthesis in Hs27 cells and further elucidated the intracellular signaling pathway responsible for emodin-induced collagen expression.

\section{Materials and methods}

Cell culture and material treatment. Human dermal fibroblasts (Hs27) were obtained from the American Type Culture Collection (cat. no. ATCC CRL-1634) and cultured in the Dulbecco's modified essential medium (DMEM; Gibco; Thermo Fisher Scientific, Inc.) supplemented with $10 \%$ fetal bovine serum and maintained in an incubator with a $5 \% \mathrm{CO}_{2}$ humidified atmosphere at $37^{\circ} \mathrm{C}$. For all experiments, Hs 27 cells were used between passage numbers five and ten. For time- and dose-dependent treatments, Hs27 cells were serum-starved for $24 \mathrm{~h}$ before exposure to the YIGSR peptide and emodin at specific doses and times. The synthetic YIGSR peptide was purchased from Anygen. emodin (cat. no. E7881), TGF- $\beta$ (cat. no. T7039), and the inhibitors U0126 (cat. no. 662009) and compound c (cat. no. 171260) were purchased from Sigma-Aldrich (Merck KGaA).

Reverse transcription-quantitative-PCR. Total RNA was extracted using the TRIzol reagent (Invitrogen; Thermo Fisher Scientific, Inc.), and cDNA was reverse transcribed from $1 \mu \mathrm{g}$ of total RNA using oligo (dT) primers and murine leukemia virus reverse transcriptase. The temperature protocol for reverse transcription was as follows: $25^{\circ} \mathrm{C}$ for $10 \mathrm{~min}$ and $37^{\circ} \mathrm{C}$ for $120 \mathrm{~min}$, followed by heat inactivation at $85^{\circ} \mathrm{C}$ for $5 \mathrm{~min}$. A total volume of $20 \mu \mathrm{l}$ PCR amplification mixtures were prepared by mixing $10 \mu \mathrm{l}$ of $2 \mathrm{X}$ SYBR-Green I Premix ExTaq (Takara Bio, Inc.), $2 \mu \mathrm{l}$ primer mix ( $1 \mu \mathrm{M}$ forward and $1 \mu \mathrm{M}$ reverse primers), and $8 \mu 1$ diluted cDNA templates. Real-Time quantitative PCR was performed on the CFX96 real-time PCR system (Bio-Rad Laboratories, Inc.) using the following conditions: $95^{\circ} \mathrm{C}$ for $1 \mathrm{~min}$, followed by $40 \mathrm{ampli}$ fication cycles comprising $95^{\circ} \mathrm{C}$ for $15 \mathrm{sec}, 60^{\circ} \mathrm{C}$ for $15 \mathrm{sec}$ (annealing), and $72^{\circ} \mathrm{C}$ for $30 \mathrm{sec}$. After amplification, melting curve analysis was performed according to manufacturer's instructions (Bio-Rad Laboratories, Inc.). Primer sequences for collagen were as follows: COL1A1 forward, 5'-gaacgcgtgtcatccettgt-3'; COL1A1 reverse, 5'-gaacgaggtagtctttcagcaaca-3'; COL1A2 forward, 5'-cetggtgctaaaggagaaagagg-3'; COL1A2 reverse 5'-atcaccacgacttccagcagga-3'; COL $2 A 1$ forward, 5'-cct ggcaaagatggtgagacag-3'; COL2A1 reverse, 5'-cctggttttccacct tcacctg-3'; COL3A1 forward, 5'-tggtctgcaaggaatgcctgga-3'; COL3A1 reverse, 5'-tctttccetgggacaccatcag-3'; COL4A3 forward, 5'-ggacaaaggagaaccaggtctc-3'; COL4A3 reverse, 5'-agtgctgcccaaatctcetctg-3'; COL5A1 forward, 5'-cacaacttg cetgatggaataaca-3', and COL5A1 reverse, 5'-gcagggtacagctgc ttggt- 3 '. Collagen expression was measured using the $2^{-\Delta \Delta C q}$ assay (32) and normalized against $G A P D H$.

MTT assay. For the MTT assay, Hs27 cells were seeded in 96-well culture plates $\left(1 \times 10^{4}\right.$ cells/well) and cultured for $24 \mathrm{~h}$. After serum starvation for $24 \mathrm{~h}$, cells were exposed to emodin with the given dose $(0.05,0.1,0.5,1,3$ and $5 \mu \mathrm{M})$ and time conditions. After discarding the media, cells were treated with $0.5 \mathrm{mg} / \mathrm{ml}$ MTT (Sigma-Aldrich; Merck KGaA) dissolved in serum-free media for $3 \mathrm{~h}$ in a $37^{\circ} \mathrm{C} \mathrm{CO}_{2}$ incubator. After discarding the solution, $100 \mu \mathrm{l}$ DMSO was added to each well, and the plate was vortexed for $10 \mathrm{~min}$. The absorbance of the MTT solution was measured at a wavelength of $540 \mathrm{~nm}$.

Fluorescence-activated cell sorting (FACS) analysis. For apoptosis analysis, Hs27 cells were seeded in 6-well culture plates and exposed to a given dose of emodin $(1$ and $5 \mu \mathrm{M})$ for $24 \mathrm{~h}$. After trypsinization, the cells were detached and harvested by centrifugation $\left(400 \mathrm{xg}\right.$ for $5 \mathrm{~min}$ at $\left.4^{\circ} \mathrm{C}\right)$. Collected cells were stained with FITC-Annexin V (cat. no. 556419; BD Biosciences) and 7-ADD (cat. no. 559925; BD Biosciences) in the dark for $20 \mathrm{~min}$. Living and apoptotic populations were detected using flow cytometry (FACS Aria; BD Biosciences).

Immunoblotting. The following antibodies were used for immunoblotting: COL1 (Rockland Immunochemicals; cat. no. 600-401-103-0.5), phospho-5' AMP-activated protein kinase (AMPK; Tyr ${ }^{172}$; Cell Signaling Technology, Inc.; cat. no. 2535), phospho-Smad2 (Ser465/467; Cell Signaling Technology, Inc.; cat. no. 3108), phospho-ERK (Thr ${ }^{202} / \mathrm{Tyr}^{204}$; Abcam; cat. no. ab214362), MMP-1 (Cell Signaling Technology, Inc.; cat. no. 54376) and $\beta$-actin (MP Biomedicals; cat. no. 08691331). Immunoblotting was performed by harvesting the treated cells and by isolating the total proteins. To prepare total cell lysates, the cells were washed with cold phosphate-buffered saline and lysed in cold lysis buffer [in mM: 40 HEPES (pH 7.5), $120 \mathrm{NaCl}$, 1 EDTA, 10 pyrophosphate, 10 glycerophosphate, $50 \mathrm{NaF}$, $1.5 \mathrm{Na}_{3} \mathrm{VO}_{4}, 1$ PMSF, $5 \mathrm{MgCl}_{2}, 0.5 \%$ Triton X-100 and protease-inhibitor mixture). After determining protein concentration using a Bradford assay, protein lysates were subsequently denatured by boiling in Lammeli sample buffer for $10 \mathrm{~min}$ at $95^{\circ} \mathrm{C}$. A total of $15 \mu \mathrm{g}$ protein was loaded and separated by $8 \%$ SDS-PAGE gel, and transferred onto nitrocellulose membranes. The membranes were subsequently blocked for $30 \mathrm{~min}$ at room temperature with $5 \%$ non-fat milk in Tris-buffered saline containing $0.05 \%$ Tween-20 (TBS-T; $\mathrm{pH}$ 7.6), followed by incubation with primary antibodies $(1: 1,000)$. After washing the membranes three times with TBS-T, blots were incubated with HRP-conjugated secondary antibody (SeraCare KPL; goat anti-rabbit; cat. no. 5220-0336; anti-mouse; cat. no. 5220-0342; each, 1:5,000) for $1 \mathrm{~h}$ at room temperature, washed three times with TBS-T and detected by enhanced chemiluminescence (ECL system; GE Healthcare Bio-Sciences). Densitometric analysis was performed using 
A
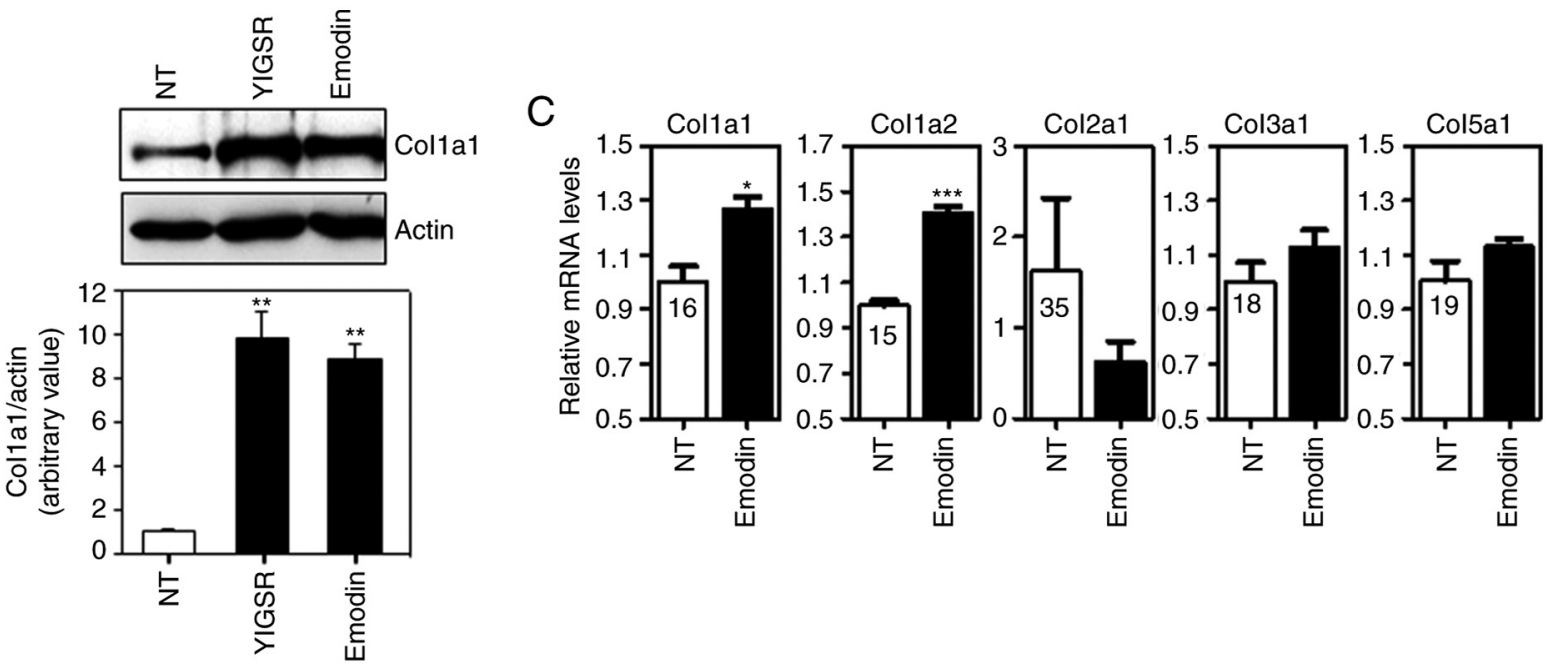

$\mathrm{B}$
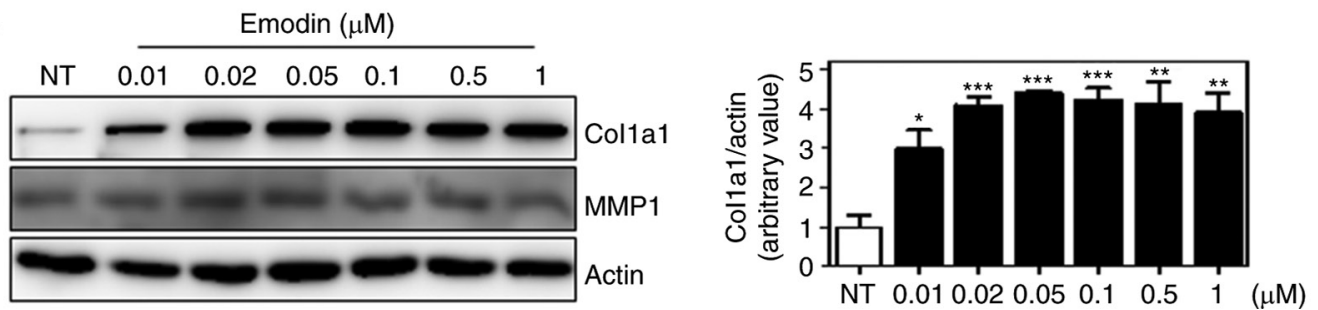

Figure 1. Emodin induces collagen synthesis in Hs27 dermal fibroblasts. (A) Immunoblotting of collagen type I following treatment with the YIGSR peptide and emodin. After 12-h treatment with $1 \mu \mathrm{M}$ of each compound, cell lysates were electrophoresed and blotted. (B) Collagen type I and MMP-1 levels after dose-dependent emodin treatment for $12 \mathrm{~h}$. (C) Transcript levels of various collagen types after emodin treatment. Normalization was performed using GAPDH. Values are represented as mean $\pm \mathrm{SEM}$. ${ }^{*} \mathrm{P}<0.05 ;{ }^{* *} \mathrm{P}<0.01 ;{ }^{* * *} \mathrm{P}<0.001$. Ct values are shown in the graph. $\mathrm{NT}$, non-treated; MMP, matrix metalloprotease.

the ImageJ software (v.1.51; http://rsbweb.nih.gov/ij/index. html) and Multigauge software (Fujifilm). Data were obtained from three independent experiments.

Statistical analysis. All data were evaluated using the GraphPad software 5 (GraphPad Software, Inc.) and are expressed as mean \pm SEM. The significant differences among groups were determined by one-way ANOVA with Dunnett's multiple comparison analysis. Comparison between two groups was analyzed by unpaired 2-tailed Student's t-test. $\mathrm{P}<0.05$ was considered to indicate a statistically significant difference.

\section{Results}

Emodin induces collagen synthesis. To investigate the effects of emodin on type I collagen expression in dermal fibroblasts, Hs27 human dermal fibroblasts were initially exposed to emodin for $12 \mathrm{~h}$ (Fig. 1A). Hs27 cells were also treated with YIGSR, a peptide that induces collagen synthesis in Hs27 cells (33). As shown in Fig. 1A, YIGSR and emodin significantly increased protein levels of type I collagen, and these levels positively associate with emodin concentration (Fig. 1B). MMP-1 is a well-known protease that degrades collagen proteins. To investigate whether emodin affected MMP-1 expression, we analyzed MMP-1 levels following dose-dependent emodin treatment. As shown in Fig. 1B, no significant changes in MMP-1 levels were observed, indicating that the increase in type I collagen by emodin treatment was not caused by MMP-1 downregulation. Subsequently, the effect of emodin on mRNA expression was determined by qPCR analysis. Similar to protein levels, exposure to emodin increased transcript levels of type I collagen without any effects on types II, III and V collagen (Fig. 1C). Type IV collagen genes were not detectable in Hs27 cells (data not shown). This suggests that emodin specifically induces type I collagen expression in vitro.

Emodin does not affect cell viability. To verify the effect of emodin on cell viability an MTT assay was performed. In particular, relatively high doses of emodin were used for the viability assay to exclude potential cytotoxicity with increased concentration. As a result, there was no significant changes in cell viability at varying concentrations of emodin (Fig. 2A). Light microscopy images further demonstrated that 24-h emodin treatment did not induce any changes in fibroblast cell morphology (Fig. 2B). Additionally, the number of apoptotic cells following emodin treatment was evaluated by flow cytometry, with Fig. 2C showing that the percentage of apoptotic cells was similar between vehicle- and emodin-treated groups. These results indicate that emodin increases type I collagen without affecting cell viability.

Emodin activates the ERK and AMPK pathways in Hs27 fibroblasts. Several signaling pathways are involved in collagen synthesis, including the focal adhesion kinase (FAK), ERK, p38 mitogen-activated protein kinase and AKT pathways (34-37). Moreover, 5' AMP-activated protein kinase 
A

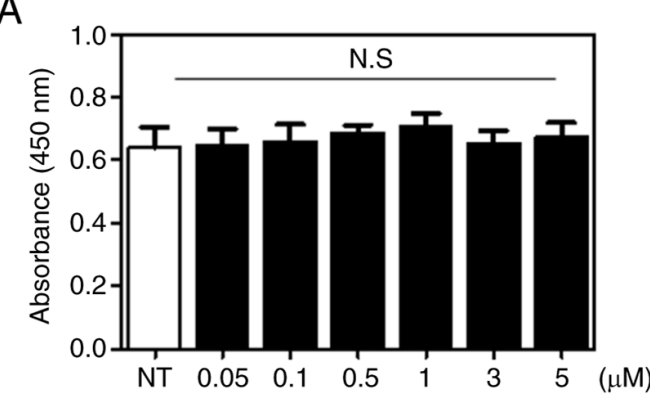

$\mathrm{B}$

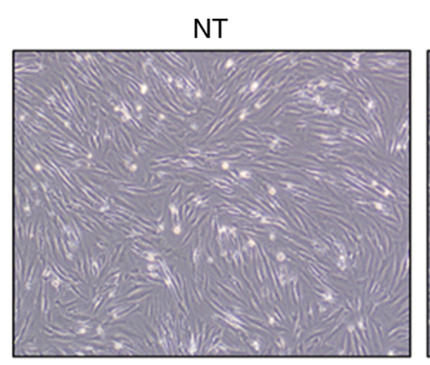

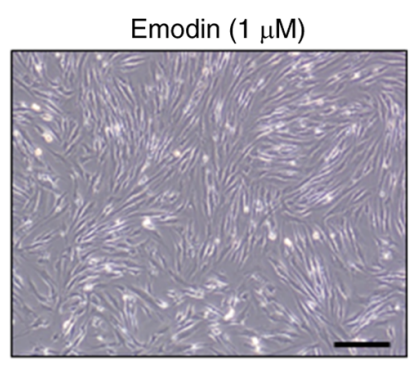

Emodin

C

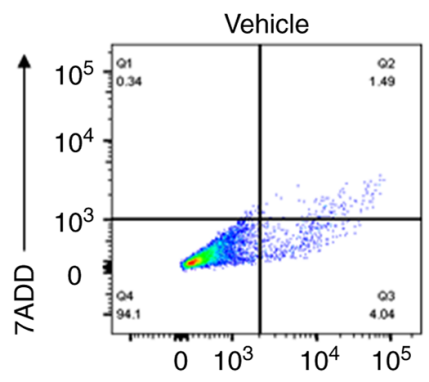

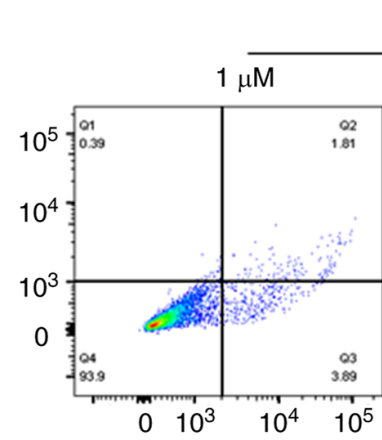

$5 \mu \mathrm{M}$

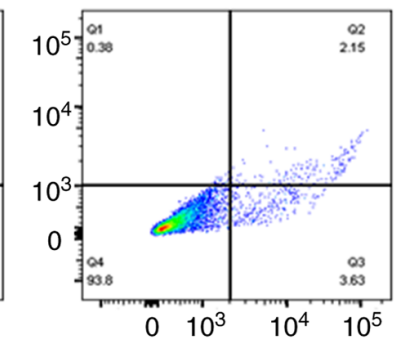

FITC Annexin V

Figure 2. Cell-survival rates are not affected by emodin treatment. (A) Survival of Hs27 cells after dose-dependent emodin treatment for 24 h. (B) Light microscopy images obtained after $1 \mu \mathrm{M}$ emodin treatment for $12 \mathrm{~h}$. Scale bar, $100 \mu \mathrm{m}$. (C) Following emodin treatment for $24 \mathrm{~h}$, apoptosis was detected by FACS analysis using Annexin V/7-ADD double staining. N.S., not significant; NT, non-treated.
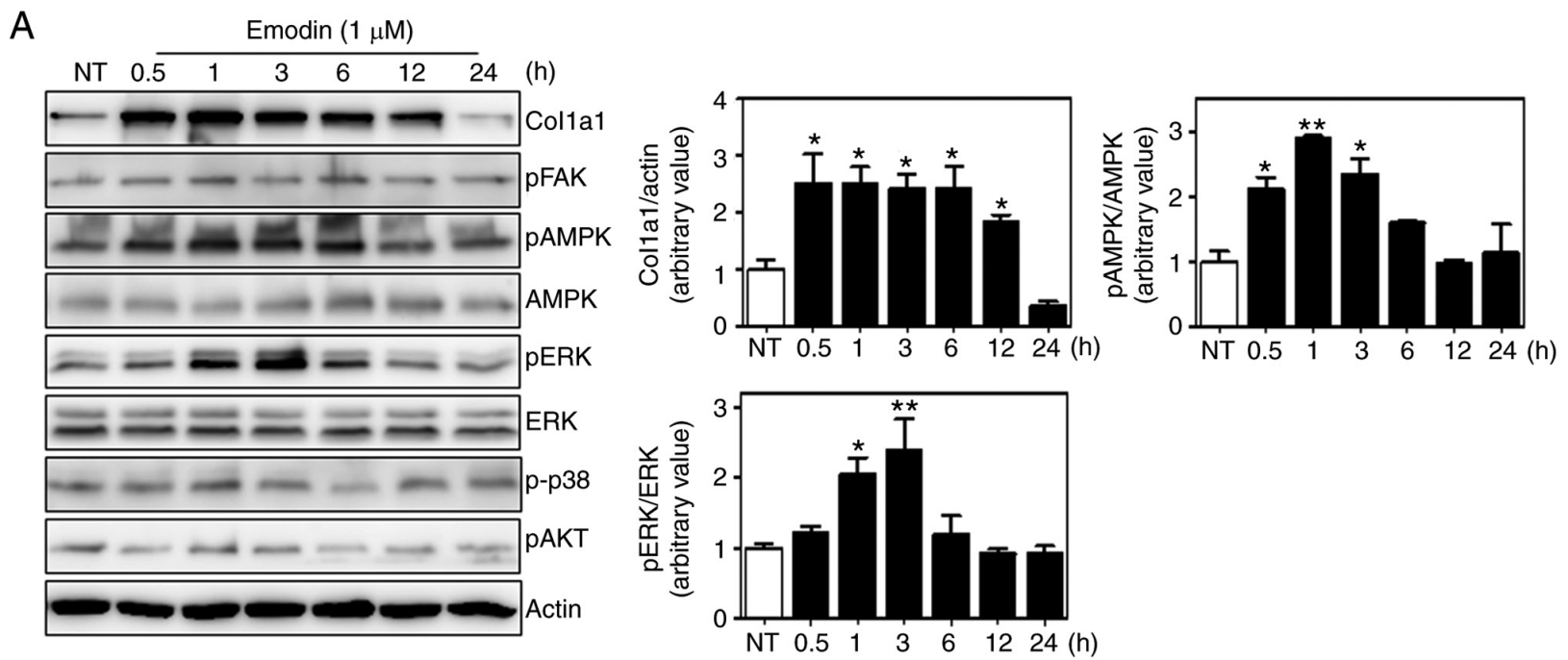

B

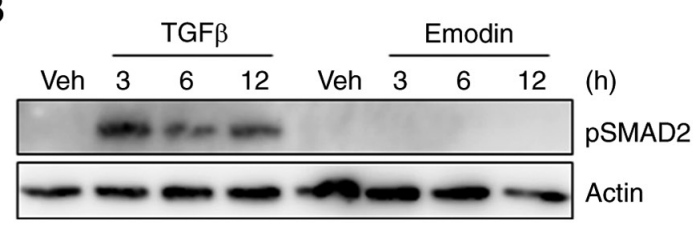

Figure 3. Activation of the ERK and AMPK pathways by emodin in Hs27 cells. (A) Lysates from cells incubated in the presence of emodin for the indicated times were subjected to immunoblot assay using various antibodies (left). Quantification of phospho/total ERK and AMPK levels (right). Values are represented as mean \pm SEM. " $\mathrm{P}<0.05 ;{ }^{* *} \mathrm{P}<0.01$. (B) Smad2 phosphorylation was analyzed following either TGF- $\beta(2.5 \mathrm{ng} / \mathrm{ml})$ or emodin (1 $\left.\mu \mathrm{M}\right)$ treatment at the indicated time. NT, non-treated; FAK, focal adhesion kinase; TGF, transforming growth factor; AMPK, 5' AMP-activated protein kinase.

(AMPK) also appears to affect collagen expression $(38,39)$. To investigate whether these pathways were responsible for emodin-induced type I collagen synthesis, the phosphorylation of each component was analyzed, and found that ERK and 
A
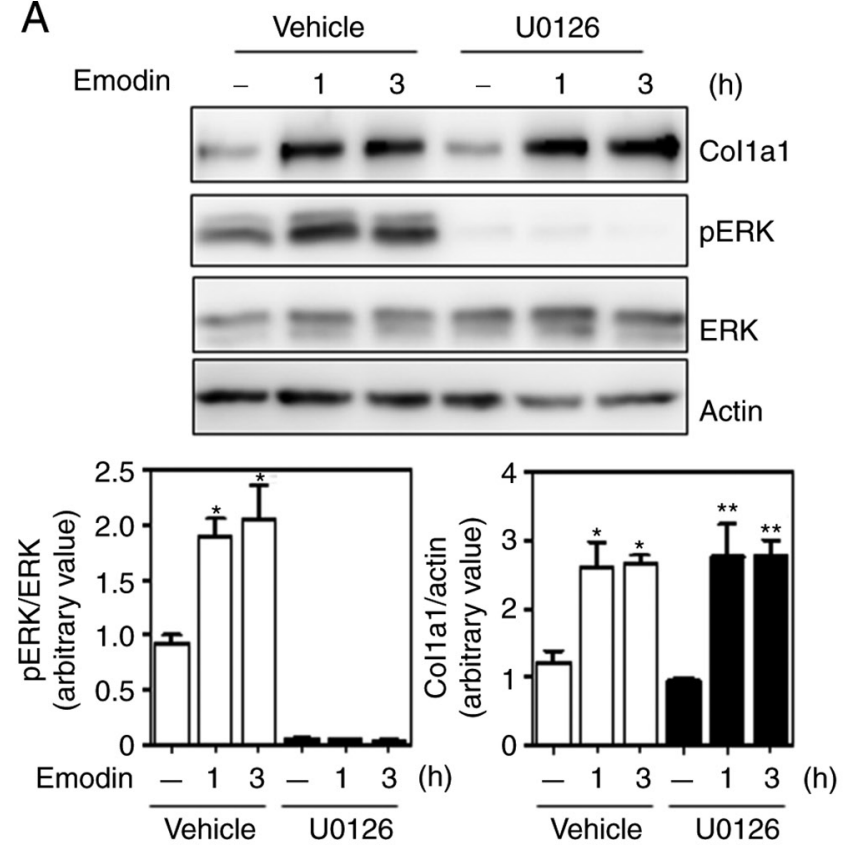

$\mathrm{B}$
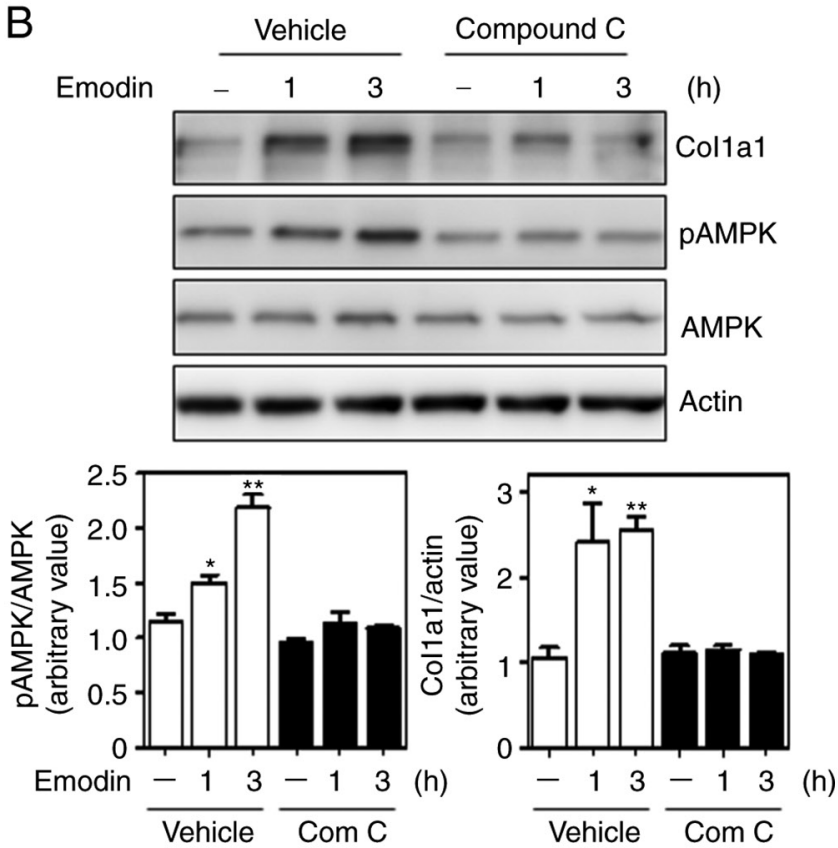

Figure 4. Inhibition of the AMPK pathway decreases type I collagen expression. Effects of ERK and AMPK inhibitors on emodin-induced type I collagen synthesis. Cells were pre-incubated with $10 \mu \mathrm{M}$ MEK inhibitor U0126 (A) or the AMPK inhibitor compound c (B) for 30 min and subsequently treated with emodin for the indicated time. ${ }^{*} \mathrm{P}<0.05 ;{ }^{* *} \mathrm{P}<0.01$. AMPK, 5 ' AMP-activated protein kinase.

AMPK phosphorylation was increased by $\sim 2.5$-fold at $3 \mathrm{~h}$ after emodin treatment relative to untreated cells and without any effect on total protein levels (Fig. 3A). Phosphorylated p38, AKT and FAK were normalized with housekeeping protein, actin. In contrast to AMPK and ERK, no significant differences were observed in the phosphorylation of these proteins between control and emodin treatment at each time point. Total protein levels of $\mathrm{p} 38$, AKT and FAK were not examined, because there were no changes in the phosphorylation status. Since TGF- $\beta$ signaling is an important regulatory pathway of collagen expression (40), the phosphorylation status of downstream molecules were also measured, which demonstrated that Smad2 phosphorylation was also unaffected by emodin treatment (Fig. 3B). Thus, the TGF- $\beta$ pathway is not involved in emodin-induced collagen synthesis.

Inhibition of the AMPK pathway prevents emodin-induced type I collagen synthesis. To determine which of the two pathways (ERK and AMPK) affected emodin-induced collagen expression, Hs27 cells were treated with the chemical inhibitor U0126 to suppress the ERK pathway. Although U0126 sufficiently decreased ERK phosphorylation, emodin-induced type I collagen expression remained similar to that in the vehicle-treated group (Fig. 4A). In marked contrast, collagen levels were largely inhibited by the AMPK inhibitor, compound c (Fig. 4B), suggesting AMPK as a crucial regulatory enzyme for emodin-induced type I collagen expression.

\section{Discussion}

The present study demonstrated that emodin increases type I collagen transcripts and protein levels without affecting the collagen-degradation pathway in Hs27 cells. Furthermore, the varying concentrations of emodin used in the present study induced type I collagen expression without any effect on cellular viability. The present study clearly reveals a new function for emodin through its effect on collagen type I synthesis in human dermal fibroblasts.

The results of the present study indicate that emodin increases the phosphorylation of ERK1/2 and AMPK within $3 \mathrm{~h}$. Although a previous study has reported that activation of ERK induces the expression of type I collagen in human fibroblasts (34), contrasting results have also been published, showing that activation of ERK1/2 by IL-18 or ceramide inhibits type I collagen expression $(41,42)$. Additionally, the AMPK pathway exerts inconsistent effects on collagen synthesis. For example, 5-aminoimidazole-4-carboxamide-ribonucleoside (AICAR), an AMPK activator, promotes collagen deposition and improves scar formation by promoting myofibroblast maturation in the scar of aged ischemic hearts (38). In rat kidney fibroblasts and human embryonic kidney cells, activation of AMPK $\alpha 1$ induces fibroblast activation and increases ECM deposition, including fibronectin and type I collagen (43). However, other studies report that collagen production and secretion are decreased by AMPK phosphorylation in renal and kidney fibroblasts $(44,45)$. These studies suggest that both the ERK1/2 and AMPK pathways have varying effects on collagen metabolism depending on the cell type, culture conditions, and presence of other cytokines. To elucidate the role of each pathway and collagen expression in human dermal fibroblasts, the conventional chemical inhibitors U0126 or compound $\mathrm{c}$ were used. Pretreatment with compound c, a specific AMPK pathway inhibitor, largely suppressed emodin-induced collagen levels, thereby indicating that AMPK activation by emodin was responsible for collagen synthesis. By contrast, the ERK1/2 pathway inhibition by U0126 did not suppress emodin-induced collagen expression. 
Wound healing is a complicated process controlled by cell-ECM interactions and numerous growth factors. Among these, collagen types I and III play a critical role during wound repair by recruiting fibroblasts and increasing deposition of new collagen in skin, bone and blood vessels (46). A previous report has shown that emodin inhibits fibronectin and type III collagen synthesis by suppressing the p38 and ERK pathways in the kidney (47). Additionally, Liu et al (48) have shown that emodin inhibits collagen synthesis by inhibiting the TGF- $\beta 1 /$ ADAMTS-1 signaling pathway in pulmonary fibroblasts. However, inhibition of these pathways were not observed following emodin treatment. Although the reason for this difference remains unknown, one possibility is that these studies used long-term treatment with relatively high dose of emodin $>100 \mu \mathrm{M}$, which can affect cell viability or MMP1 expression compared with the low-concentration condition. Moreover, emodin increases or suppresses ERK phosphorylation according to the cell type (49-51). Thus, it is speculated that emodin targets a different signaling pathway for collagen synthesis between skin and other fibroblasts. Importantly, the TGF- $\beta$ signaling pathway regulates type I collagen synthesis (40), and a previous study reported that emodin treatment for 7 days significantly increased $T G F-\beta 1$ expression and collagen levels in excisional wounds (28). Although Wei et al (52) showed that emodin treatment decreased collagen deposition during intestinal surgery-induced abdominal adhesion, they suggested that emodin-mediated anti-inflammatory effects might contribute to lower collagen levels in the adhesion tissues, indicating the possibility of an indirect effect. Interestingly, Xiao et al (53) showed that the AMPK pathway inhibited inflammation or angiotensin-induced TGF- $\beta$ signaling in cardiac fibroblasts, whereas another study reported that AMPK activation increased rather than suppressed TGF- $\beta$ responsiveness, by stimulating the non-canonical TGF- $\beta$ pathway in myofibroblasts (38). In the present study, Smad2 phosphorylation remained similar between vehicle and emodin treatments, indicating that emodin did not increase TGF- $\beta$ signaling in dermal fibroblasts. Given these findings, further studies are necessary to elucidate the detailed mechanisms by which emodin mediates different responses to collagen expression in each cell type.

In summary, the present study demonstrated that emodin directly increases type I collagen levels in Hs27 cells, and that AMPK activation is an important factor for collagen expression. A limitation of the study is that newborn foreskin fibroblasts (Hs27) were the only cells for confirming the overall results. Previous studies report functional differences between neonatal and adult dermal fibroblasts in terms of ECM components and migration capacity $(54,55)$; therefore, determining whether emodin can increase type I collagen levels in adult dermal fibroblasts is worthwhile. As collagen synthesis is decreased in aged skin (56), and collagen-induction therapy is considered a safe treatment strategy for wrinkles and scars, emodin represents a potential therapeutic agent for alleviating skin aging. Nevertheless, further in vivo investigations are warranted to support these results.

\section{Acknowledgements}

Not applicable.

\section{Funding}

This research was supported by the KBRI Basic Research Program (grant no. 20-BR-02-012) funded by the Ministry of Science and ICT and by the Basic Science Research Program through the National Research Foundation of Korea funded by the Ministry of Education (grant no. 2018R1D1A1B07043929). This research was also supported by grants from the National Cancer Center, Republic of Korea (grant no. NCC 1810861-1) and by a National Research Foundation of Korea grant funded by the Korean government (grant no. 2020R1C1C1005500).

\section{Availability of data and materials}

The datasets used and/or analyzed during the current study are available from the corresponding author on reasonable request.

\section{Authors' contributions}

PS wrote the manuscript and performed the experiments. HSJ, YWK and SB contributed to the conceptualization and design of the experiments. YK, BA and WSS performed the experiments. $\mathrm{JH}$ and DL interpreted the data and reviewed the manuscript. SHR helped analyze the data and revise the manuscript. PS and YK confirm the authenticity of all the raw data. PS and JHY supervised the entire project, conceived the study and wrote the original draft. All authors read and approved this manuscript.

\section{Ethics approval and consent to participate}

Not applicable.

\section{Patient consent for publication}

Not applicable.

\section{Competing interests}

The authors declare that they have no competing interests.

\section{References}

1. Zhao X, Psarianos P, Ghoraie LS, Yip K, Goldstein D, Gilbert R, Witterick I, Pang H, Hussain A, Lee JH, et al: Metabolic regulation of dermal fibroblasts contributes to skin extracellular matrix homeostasis and fibrosis. Nat Metab 1: 147-157, 2019.

2. Avila Rodriguez MI, Rodriguez Barroso LG and Sánchez ML: Collagen: A review on its sources and potential cosmetic applications. J Cosmet Dermatol 17: 20-26, 2018.

3. de Araújo R, Lôbo M, Trindade K, Silva DF and Pereira N: Fibroblast growth factors: A controlling mechanism of skin aging. Skin Pharmacol Physiol 32: 275-282, 2019.

4. Mäkitie RE, Costantini A, Kämpe A, Alm JJ and Mäkitie O: New insights into monogenic causes of osteoporosis. Front Endocrinol (Lausanne) 10: 70, 2019.

5. Irawan V, Sung TC, Higuchi A and Ikoma T: Collagen scaffolds in cartilage tissue engineering and relevant approaches for future development. Tissue Eng Regen Med 15: 673-697, 2018.

6. Armendariz-Borunda J, Katayama K and Seyer JM: Transcriptional mechanisms of type I collagen gene expression are differentially regulated by interleukin-1 beta, tumor necrosis factor alpha, and transforming growth factor beta in Ito cells. J Biol Chem 267: 14316-14321, 1992. 
7. Gillery P, Leperre A, Maquart FX and Borel JP: Insulin-like growth factor-I (IGF-I) stimulates protein synthesis and collagen gene expression in monolayer and lattice cultures of fibroblasts. J Cell Physiol 152: 389-396, 1992.

8. Honda N,Jinnin M, Kajihara I, Makino T,Makino K, MasuguchiS, Fukushima S, Okamoto Y, Hasegawa M, Fujimoto M and Ihn $\mathrm{H}$ TGF- $\beta$-mediated downregulation of microRNA-196a contributes to the constitutive upregulated type I collagen expression in scleroderma dermal fibroblasts. J Immunol 188: 3323-3331, 2012.

9. Mishra R,Zhu L,Eckert RL and Simonson MS: TGF-beta-regulated collagen type I accumulation: Role of Src-based signals. Am J Physiol Cell Physiol 292: C1361-C1369, 2007.

10. Murad S, Sivarajah A and Pinnell SR: Prolyl and lysyl hydroxylase activities of human skin fibroblasts: Effect of donor age and ascorbate. J Invest Dermatol 75: 404-407, 1980.

11. Tsuji-Naito K, Ishikura S, Akagawa M and Saeki H: $\alpha$-Lipoic acid induces collagen biosynthesis involving prolyl hydroxylase expression via activation of TGF- $\beta$-Smad signaling in human dermal fibroblasts. Connect Tissue Res 51: 378-387, 2010

12. Yamauchi M and Sricholpech M: Lysine post-translational modifications of collagen. Essays Biochem 52: 113-133, 2012.

13. Tsutsumi Y, Kakumu S, Yoshioka K, Arao M, Inoue $M$ and Wakita T: Effects of various cytokines on collagen synthesis by normal rat hepatocytes in primary cultures and fibroblasts Digestion 44: 191-199, 1989.

14. Nakamuta M, Kotoh K, Enjoji M and Nawata H: Effects of fibril- or fixed-collagen on matrix metalloproteinase- 1 and tissue inhibitor of matrix metalloproteinase-1 production in the human hepatocyte cell line HLE. World J Gastroenterol 11: 2264-2268, 2005.

15. Quan T, Qin Z, Xu Y, He T, Kang S, Voorhees JJ and Fisher GJ: Ultraviolet irradiation induces CYR61/CCN1, a mediator of collagen homeostasis, through activation of transcription factor AP-1 in human skin fibroblasts. J Invest Dermatol 130: 1697-1706, 2010.

16. Ganceviciene R, Liakou AI, Theodoridis A, Makrantonaki E and Zouboulis CC: Skin anti-aging strategies. Dermatoendocrinol 4: 308-319, 2012

17. Galicka A and Nazaruk J: Stimulation of collagen biosynthesis by flavonoid glycosides in skin fibroblasts of osteogenesis imperfecta type I and the potential mechanism of their action. Int J Mol Med 20: 889-895, 2007.

18. Kwok HH, Yue PY, Mak NK and Wong RN: Ginsenoside $\mathrm{Rb}(1)$ induces type I collagen expression through peroxisome proliferator-activated receptor-delta. Biochem Pharmacol 84 532-539, 2012

19. Lucarini M, Sciubba F, Capitani D, Di Cocco ME, D'Evoli L, Durazzo A, Delfini M and Lombardi Boccia G: Role of catechin on collagen type I stability upon oxidation: A NMR approach. Nat Prod Res 34: 53-62, 2020.

20. Dong X, Fu J, Yin X, Cao S, Li X, Lin L and Huyiligeqi; Ni J: Emodin: A review of its pharmacology, toxicity and pharmacokinetics. Phytother Res 30: 1207-1218, 2016.

21. Wang M, Zhao R, Wang W, Mao X and Yu J: Lipid regulation effects of Polygoni Multiflori Radix, its processed products and its major substances on steatosis human liver cell line L02. J Ethnopharmacol 139: 287-293, 2012.

22. Wang W, Zhou Q, Liu L and Zou K: Anti-allergic activity of emodin on IgE-mediated activation in RBL-2H3 cells. Pharmacol Rep 64: 1216-1222, 2012.

23. Andersen DO, Weber ND, Wood SG, Hughes BG, Murray BK and North JA: In vitro virucidal activity of selected anthraquinones and anthraquinone derivatives. Antiviral Res 16: 185-196, 1991.

24. Hwang JK, Noh EM, Moon SJ, Kim JM, Kwon KB, Park BH, You YO, Hwang BM, Kim HJ, Kim BS, et al: Emodin suppresses inflammatory responses and joint destruction in collagen-induced arthritic mice. Rheumatology (Oxford) 52: 1583-1591, 2013.

25. Srinivas G, Babykutty S, Sathiadevan PP and Srinivas P: Molecular mechanism of emodin action: Transition from laxative ingredient to an antitumor agent. Med Res Rev 27: 591-608, 2007.

26. Ahn SM, Kim HN, Kim YR, Choi YW, Kim CM, Shin HK and Choi BT: Emodin from Polygonum multiflorum ameliorates oxidative toxicity in HT22 cells and deficits in photothrombotic ischemia. J Ethnopharmacol 188: 13-20, 2016.

27. Gundogdu G, Gundogdu K, Nalci KA, Demirkaya AK, Yılmaz Taseı S, Demirkaya Miloglu F, Senol O and Hacimuftuoglu A The effect of parietin isolated from rheum ribes $\mathrm{L}$ on in vitro wound model using human dermal fibroblast cells. Int J Low Extrem Wounds 18: 56-64, 2019.
28. Tang T, Yin L, Yang J and Shan G: Emodin, an anthraquinone derivative from Rheum officinale Baill, enhances cutaneous wound healing in rats. Eur J Pharmacol 567: 177-185, 2007.

29. Xiao D, Zhang Y, Wang R, Fu Y, Zhou T, Diao H, Wang Z, Lin Y, LiZ, Wen L, et al: Emodin alleviates cardiac fibrosis by suppressing activation of cardiac fibroblasts via upregulating metastasis associated protein 3. Acta Pharm Sin B 9: 724-733, 2019.

30. Kapoor M, Howard R, Hall I and Appleton I: Effects of epicatechin gallate on wound healing and scar formation in a full thickness incisional wound healing model in rats. Am J Pathol 165: 299-307, 2004.

31. Lin LX, Wang P, Wang YT, Huang Y, Jiang L and Wang XM: Aloe vera and Vitis vinifera improve wound healing in an in vivo rat burn wound model. Mol Med Rep 13: 1070-1076, 2016.

32. Livak KJ and Schmittgen TD: Analysis of relative gene expression data using real-time quantitative PCR and the 2(-Delta Delta $\mathrm{C}(\mathrm{T})$ ) method. Methods 25: 402-408, 2001

33. Yoon JH, Kim J, Lee H, Kim SY, Jang HH, Ryu SH, Kim BJ and Lee TG: Laminin peptide YIGSR induces collagen synthesis in Hs27 human dermal fibroblasts. Biochem Biophys Res Commun 428: 416-421, 2012.

34. Bhogal RK and Bona CA: Regulatory effect of extracellular signal-regulated kinases (ERK) on type I collagen synthesis in human dermal fibroblasts stimulated by IL-4 and IL-13. Int Rev Immunol 27: 472-496, 2008.

35. Kimoto K, Nakatsuka K, Matsuo N and Yoshioka H: p38 MAPK mediates the expression of type I collagen induced by TGF-beta 2 in human retinal pigment epithelial cells ARPE-19. Invest Ophthalmol Vis Sci 45: 2431-2437, 2004.

36. Rajshankar D, Wang Y and McCulloch CA: Osteogenesis requires FAK-dependent collagen synthesis by fibroblasts and osteoblasts. FASEB J 31: 937-953, 2017.

37. Yokoyama K, Kimoto K, Itoh Y, Nakatsuka K, Matsuo N, Yoshioka $H$ and Kubota T: The PI3K/Akt pathway mediates the expression of type I collagen induced by TGF- $\beta 2$ in human retinal pigment epithelial cells. Graefes Arch Clin Exp Ophthalmol 250: 15-23, 2012.

38. Cieslik KA, Taffet GE, Crawford JR, Trial J, Mejia Osuna P and Entman ML: AICAR-dependent AMPK activation improves scar formation in the aged heart in a murine model of reperfused myocardial infarction. J Mol Cell Cardiol 63: 26-36, 2013.

39. Crane JD, MacNeil LG, Lally JS, Ford RJ, Bujak AL, Brar IK, Kemp BE, Raha S, Steinberg GR and Tarnopolsky MA: Exercise-stimulated interleukin-15 is controlled by AMPK and regulates skin metabolism and aging. Aging Cell 14: 625-634, 2015.

40. Walton KL, Johnson KE and Harrison CA: Targeting TGF-beta mediated SMAD signaling for the prevention of fibrosis. Front Pharmacol 8: 461, 2017

41. Kim HJ, Song SB, Choi JM, Kim KM, Cho BK, Cho DH and Park HJ: IL-18 downregulates collagen production in human dermal fibroblasts via the ERK pathway. J Invest Dermatol 130: 706-715, 2010.

42. Reunanen N, Foschi M, Han J and Kahari VM: Activation of extracellular signal-regulated kinase $1 / 2$ inhibits type I collagen expression by human skin fibroblasts. J Biol Chem 275: 34634-34639, 2000

43. Wang Y, Jia L, Hu Z, Entman ML, Mitch WE and Wang Y: AMP-activated protein kinase/myocardin-related transcription factor-A signaling regulates fibroblast activation and renal fibrosis. Kidney Int 93: 81-94, 2018.

44. Chen KH, Hsu HH, Lee CC, Yen TH, Ko YC, Yang CW and Hung CC: The AMPK agonist AICAR inhibits TGF- $\beta 1$ induced activation of kidney myofibroblasts. PLoS One 9: e106554, 2014.

45. Lu J, Shi J, Li M, Gui B, Fu R, Yao G, Duan Z, Lv Z, Yang Y, Chen Z, et al: Activation of AMPK by metformin inhibits TGF- $\beta$-induced collagen production in mouse renal fibroblasts. Life Sci 127: 59-65, 2015.

46. Chattopadhyay S and Raines RT: Review collagen-based biomaterials for wound healing. Biopolymers 101: 821-833, 2014.

47. Zhu B, Lin Y, Zhu CF, Zhu XL, Huang CZ, Lu Y, Cheng XX and Wang YJ: Emodin inhibits extracellular matrix synthesis by suppressing p38 and ERK1/2 pathways in TGF- $\beta 1$-stimulated NRK-49F cells. Mol Med Rep 4: 505-509, 2011.

48. Liu L, Yin H, He J, Xie M, Wang Z and Xiao H: Emodin inhibits the proliferation, transdifferentiation and collagen synthesis of pulmonary fibroblasts. Xi Bao Yu Fen Zi Mian Yi Xue Za Zhi 32: 921-925, 2016 (In Chinese)

49. Leung SW, Lai JH, Wu JC, Tsai YR, Chen YH, Kang SJ, Chiang YH, Chang CF and Chen KY: Neuroprotective effects of emodin against ischemia/reperfusion injury through activating ERK-1/2 signaling pathway. Int J Mol Sci 21: 2899, 2020 
50. Lin W, Zhong M, Yin H, Chen Y, Cao Q, Wang C and Ling C: Emodin induces hepatocellular carcinoma cell apoptosis through MAPK and PI3K/AKT signaling pathways in vitro and in vivo. Oncol Rep 36: 961-967, 2016

51. Zhou X, Song B, Jin L, Hu D, Diao C, Xu G, Zou Z and Yang S: Isolation and inhibitory activity against ERK phosphorylation of hydroxyanthraquinones from rhubarb. Bioorg Med Chem Lett 16: 563-568, 2006

52. Wei G, Wu Y, Gao Q, Zhou C, Wang K, Shen C, Wang G, Wang K, Sun X and Li X: Effect of emodin on preventing postoperative intra-abdominal adhesion formation. Oxid Med Cell Longev 2017: 1740317, 2017.

53. Xiao Y, Ye J, Zhou Y, Huang J, Liu X, Huang B, Zhu L, Wu B, Zhang $G$ and Cai Y: Baicalin inhibits pressure overload-induced cardiac fibrosis through regulating AMPK/TGF- $\beta / \mathrm{Smads}$ signaling pathway. Arch Biochem Biophys 640: 37-46, 2018.
54. Krejčí E, Kodet O, Szabo P, Borský J, Smetana K Jr, Grim M and Dvořánková B: In vitro differences of neonatal and later postnatal keratinocytes and dermal fibroblasts. Physiol Res 64: 561-569, 2015.

55. Mateu R, Živicová V, Krejčí ED, Grim M, Strnad H, Vlček Č Koláŕ M, Lacina L, Gál P, Borský J, et al: Functional differences between neonatal and adult fibroblasts and keratinocytes: Donor age affects epithelial-mesenchymal crosstalk in vitro. Int $\mathrm{J}$ Mol Med 38: 1063-1074, 2016.

56. Varani J, Dame MK, Rittie L, Fligiel SE, Kang S, Fisher GJ and Voorhees JJ: Decreased collagen production in chronologically aged skin: Roles of age-dependent alteration in fibroblast function and defective mechanical stimulation. Am J Pathol 168: 1861-1868, 2006 